\title{
Global Multidimensional Poverty Index 2014
}

\author{
Sabina Alkire, Adriana Conconi, Suman Seth and Ana Vaz | June 2014
}

The Global Multidimensional Poverty Index (MPI) is an index of acute multidimensional poverty that in 2014 covers 108 developing countries. It assesses the nature and intensity of poverty at the individual level, by directly measuring the overlapping deprivations poor people experience simultaneously. It provides a vivid picture of how and where people are poor, within and across countries, regions and the world, enabling policymakers to better target their resources at those most in need.

\section{GLOBAL MPI - AT A GLANCE}

The Global MPI was developed in 2010 by OPHI and the United Nations Development Programme for UNDP's flagship Human Development Reports, and has been published in the reports since then.

The Global MPI has three dimensions and 10 indicators (see graphic below); for details of the indicators, see www.ophi.org.uk/multidimensional-poverty-index. A person is identified as multidimensionally poor (or 'MPI poor') if they are deprived in at least one third of the dimensions. The MPI is calculated by multiplying the incidence of poverty by the average intensity of poverty across the poor; as a result, it reflects both the share of people in poverty and the degree to which they are deprived.

The Global MPI is a powerful tool for policymakers because it shows us not just which people are poor and where, but also how they are poor: which disadvantages they are experiencing simultaneously. It reveals different intensities of poverty, as some people are deprived in a bigger share of indicators than others. And it can be decomposed to reveal varying rates of poverty reduction in different parts of a country, or between ethnicities, castes or other social groups.

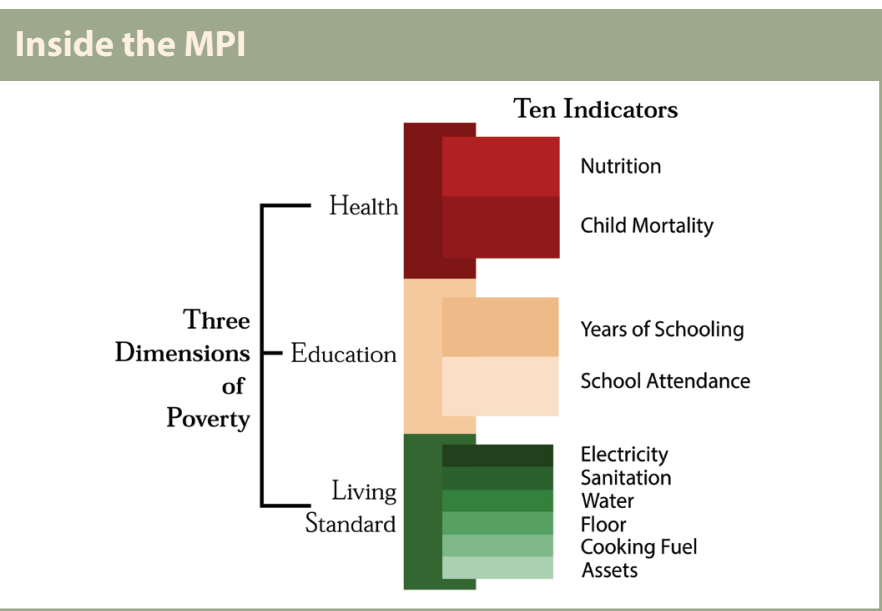

\section{Key findings from 2014}

- The MPI 2014 covers 108 countries, which are home to $78 \%$ of the world's population. Thirty percent of them - 1.6 billion people - are identified as multidimensionally poor.

- Of these 1.6 billion people, most live in South Asia (52\%), followed by Sub-Saharan Africa (29\%). Most MPI poor people (71\%) live in Middle Income Countries - Of the 1.6 billion identified as MPI poor, $85 \%$ live in rural areas; significantly higher than income poverty estimates of 70 to $75 \%$

- Nearly all countries that reduced MPI poverty also reduced inequality among the poor

- Of 34 countries for which we studied changes over time, 30 - covering $98 \%$ of the poor people across all 34 - significantly reduced multidimensional poverty

\section{A subset of the MPI poor are destitute}

In 2014, we release a new measure of destitution. A person is destitute if she is deprived in at least one-third of the same weighted indicators, but according to more extreme criteria than those used to identify the MPI poor - such as having lost two children, or having no one with at least one year of schooling at home.

- Across the 49 countries analysed so far, half of all MPI poor people are destitute

- Two-thirds of destitute people have someone with severe malnutrition at home. Over $80 \%$ have a dirt floor and over $90 \%$ practise open defecation to relieve themselves

- India is home to 343.5 million destitute people $28.5 \%$ of its population. Overall in South Asia, over 420 million people are destitute

- In Niger, $68.8 \%$ of the population is destitute - the highest share of any country

- 8 of the top 10 performers at tackling destitution over time were Low Income or Least Developed Countries 


\section{Nathalie - an individual poverty profile}

Nathalie is a vivacious 20-year old in the northeast of Cameroon. Nathalie is married, and she and her husband's other wife together have five children. The family lives in rudimentary huts with earth floors. They have no sanitation, and defecate in the bush. The water they use for drinking, cooking and washing comes from an unprotected well and they lack electricity, and cook over open fires. Her life and that of her community have worsened because bandits stole their cattle, but she stands tall and hopes for a better future.

The coloured indicators show the deprivations Nathalie faces: she is deprived in $66 \%$ of the MPI indicators.

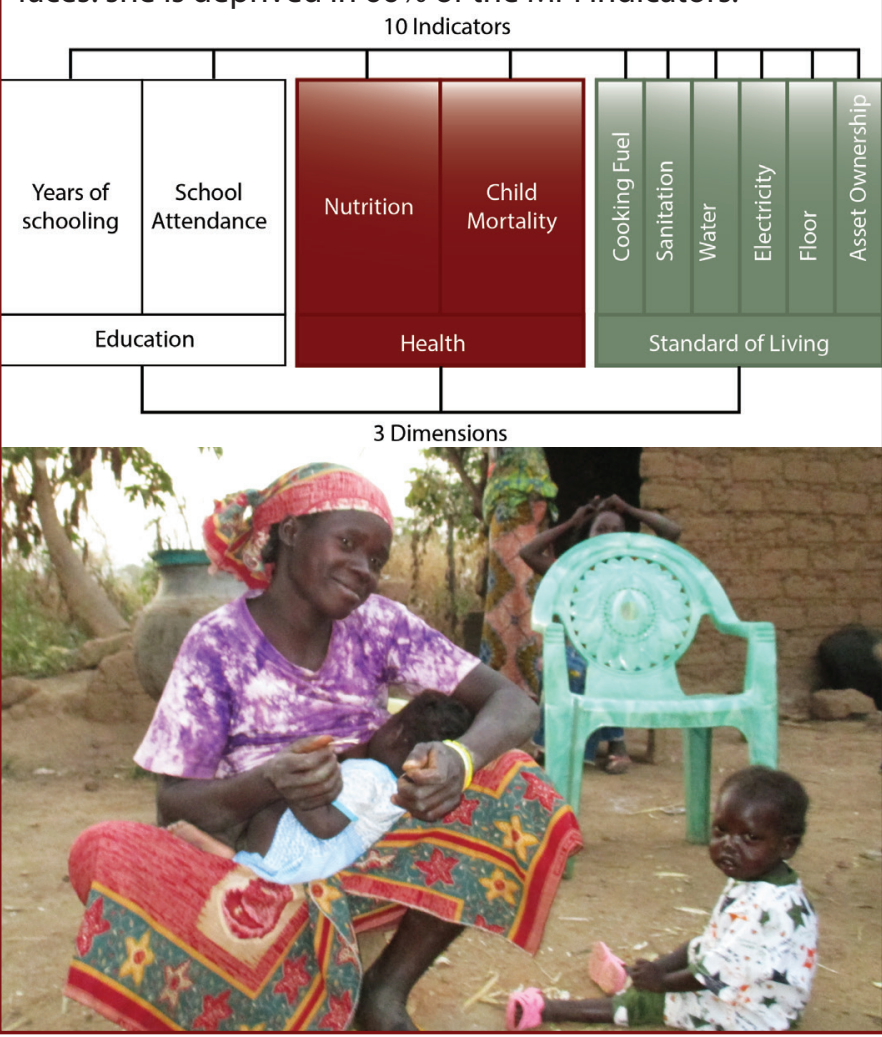

\section{DYNAMICS - HOW IS MULTIDIMENSIONAL POVERTY} CHANGING?

Our analysis of changes in multidimensional poverty over time covers 34 countries, which are home to 2.5 billion people. Of those countries, we found that the top performers in reducing MPI were Nepal (between 2006 and 2011), Rwanda (2005-2010), Ghana (2003-2008) and Bangladesh (2004-2007). All of the top ten performers except Ghana and Bolivia are Low Income Countries.

Six of the 12 sub-national regions showing the fastest absolute reductions are in Nepal. Ethnic decompositions reveal a mixed picture. In Kenya the poorest ethnic group reduced MPI the most, while in Benin, the opposite was true, exacerbating horizontal inequalities between groups. In terms of tackling destitution, the largest absolute reductions were by Ethiopia, which reduced the percentage of destitute people by 30 percentage points in 11 years.

Oxford Poverty \& Human Development Initiative (OPHI) Oxford Department of International Development (ODID) Queen Elizabeth House (QEH)

University of Oxford, Mansfield Road

Oxford OX1 3TB UK

Telephone: +44 (0)1865 271915

Email: ophi@qeh.ox.ac.uk

Website:

OPHI gratefully acknowledges support from research councils, non-governmental and governmental organisations, and private benefactors. For a list of our funders and donors, please visit our website:

\section{Global MPI 2014: Updates and coverage}

- The MPI is built using DHS, MICS, WHS surveys and national data, 2002-2013.

- Fifty-seven MPI estimations use data that are 2009-13.

- The $2014 \mathrm{MPI}$ estimates cover 108 countries and 5.4 billion people; 33 of these estimations are new in 2014.

- All MPI statistics are available for 780 sub-national regions across 69 countries.

\section{INEQUALITY AND REGIONAL DISPARITIES - WHO IS BEING LEFT BEHIND?}

In 2014, we release a separate, decomposable measure of inequality - a positive multiple of variance - and analyse inequality among the MPI poor and disparity in MPI across subnational regions (Alkire and Seth 2014). Burkina Faso had the greatest inequality among the poor out of $\mathbf{9 0}$ countries, but disparity in subnational MPI levels tended to decrease if MPI decreased - only in India did it rise.

Rural and urban poverty: Separately, in 2014 we analyse poverty levels in urban and rural areas for 105 countries. Across these countries, $85 \%$ of the MPI poor live in rural areas. The incidence of poverty in rural areas reduced significantly in 30 countries, usually faster than in urban areas, but despite urbanization, 24 countries also managed to reduce the incidence of urban poverty significantly.

\section{A GLOBAL MPI FOR POST-2015}

The Alkire Foster method that underlies the Global MPI has been used to official create national MPIs in Colombia, Mexico, Bhutan and the Philippines, each tailored to reflect national priorities. These measures are being used for allocation, targeting, and monitoring, as well as policy coordination.

In June 2013, the Multidimensional Poverty Peer Network (MPPN) was created to support the implementation of national and subnational multidimensional measures. The MPPN and OPHI have proposed that the Alkire Foster method be used to create a Global MPI2015+: a headline indicator that reflects the new agenda post-2015 and tracks deprivations in multiple aspects of poverty.

\section{REFERENCES}

Alkire, S., A. Conconi, and S. Seth (2014): 'Multidimensional Poverty Index 2014: Brief Methodological Note and Results', Oxford Poverty and Human Development Initiative, University of Oxford.

Alkire, S., A. Conconi and S. Seth (2014): 'Measuring Destitution in Developing Countries: An Ordinal Approach for Identifying Linked Subsets of the Multidimensionally Poor', OPHI Research in Progress.

Alkire, S. and Foster, J. (2011): 'Counting and Multidimensional Poverty Measurement'. Journal of Public Economics, 95(7-8): 476-487.

Alkire S, J. M. Roche, and A. Vaz (2014): 'Multidimensional Poverty Dynamics: Methodology and Results for 34 Countries'. OPHI Research in Progress.

Seth S. and S. Alkire (2014): 'Measuring and Decomposing Inequality among the Multidimensionally Poor Using Ordinal Data: A Counting Approach', OPHI Working Paper 68, Oxford Poverty and Human Development Initiative, University of Oxford. 